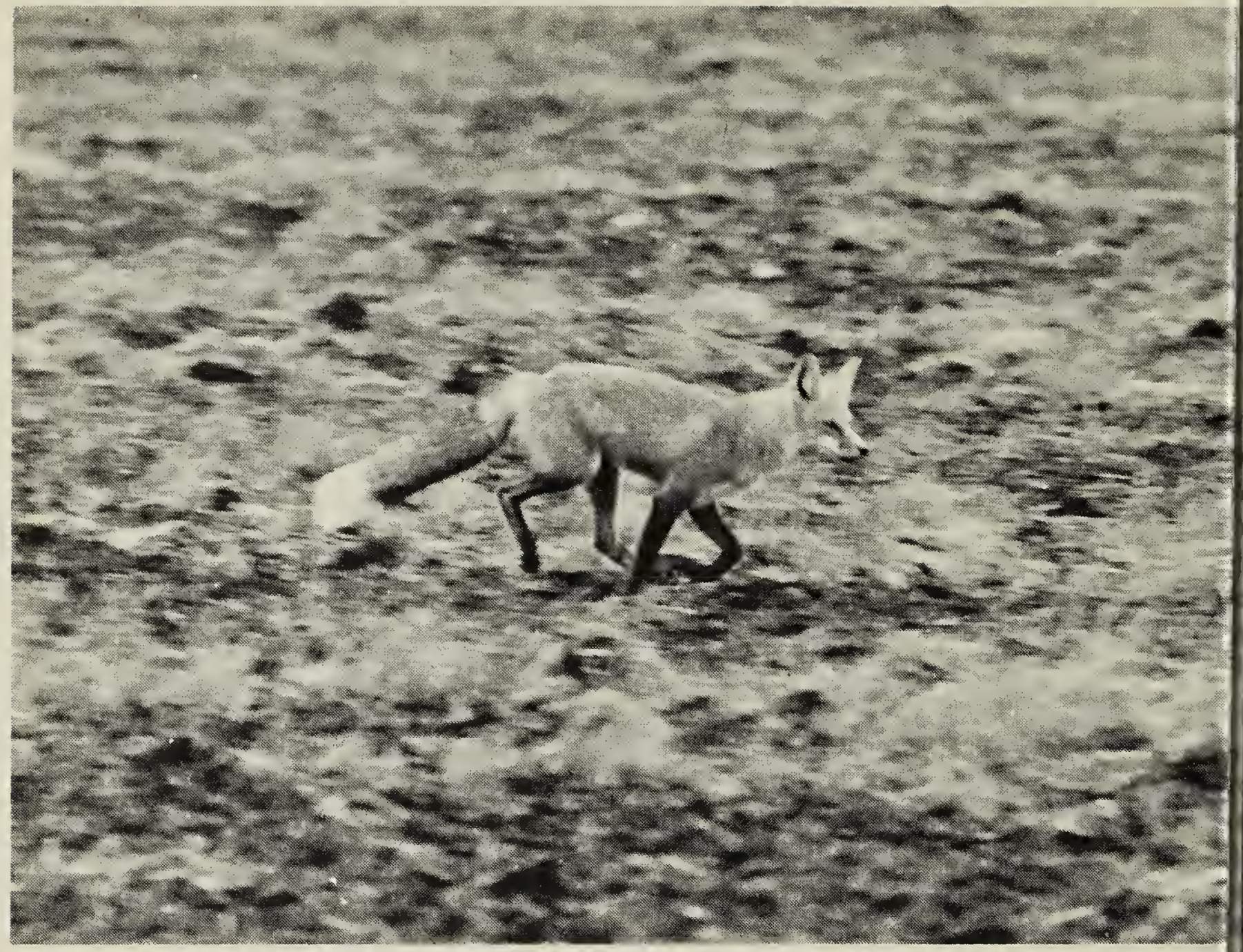

Red Fox.

Ken Lum

\section{SNOWY OWL PURSUES RED FOX EXHAUSTED BY SNOWMOBILER}

\section{by KEITH EMBERLEY*}

On January 29, 1975, at approximately $3: 20$ p.m. I noticed a snowmobiler chasing a Red Fox. This was 6 miles south and 1 mile west of Kane, Manitoba (17 miles west of Morris). The weather was clear and cold with a temperature of about $0^{\circ} \mathrm{F}$ and a $10 \mathrm{MPH}$ wind from the $\mathrm{N}$ or NW. The fox had come across a sec-

\footnotetext{
* Resource Projects,

Man. Dept. Mines, Resources and

Environmental Management

1301 Ellice Avenue,

Winnipeg, Manitoba.
}

tion road and I estimated it had b running for a good half mile or $\mathrm{mc}$ On noticing my stopped car snowmobiler took off to the wes continued watching the fox from east road with binoculars. The gradually stopped running after tering a cultivated field and remai very still, apparently exhausted by chase. Then I noticed a male Sn Owl come into view and make passes about 5 feet over the fox. fox raised itself and the owl then $t$ east toward my car; it perched $d$ : telephone pole. The fox began to $\mathrm{m}$ off south, stopping and resting at, proximately 50 -foot intervals. A it did so, the Snowy Owl started sc $h$ along a telephone line, landing a $n$. ber of poles further down, follov the fox. Both fox and owl finally $\downarrow$, out of my view. 